Document downloaded from:

http://hdl.handle.net/10251/31761

This paper must be cited as:

María-Antonia Serrano; J. Cañada; Moreno Esteve, J. (2011). Solar UV exposure of Primary Schoolchildren in Valencia, Spain.. Photochemical and Photobiological Sciences. 10(4):1523. doi:10.1039/COPP00153H.

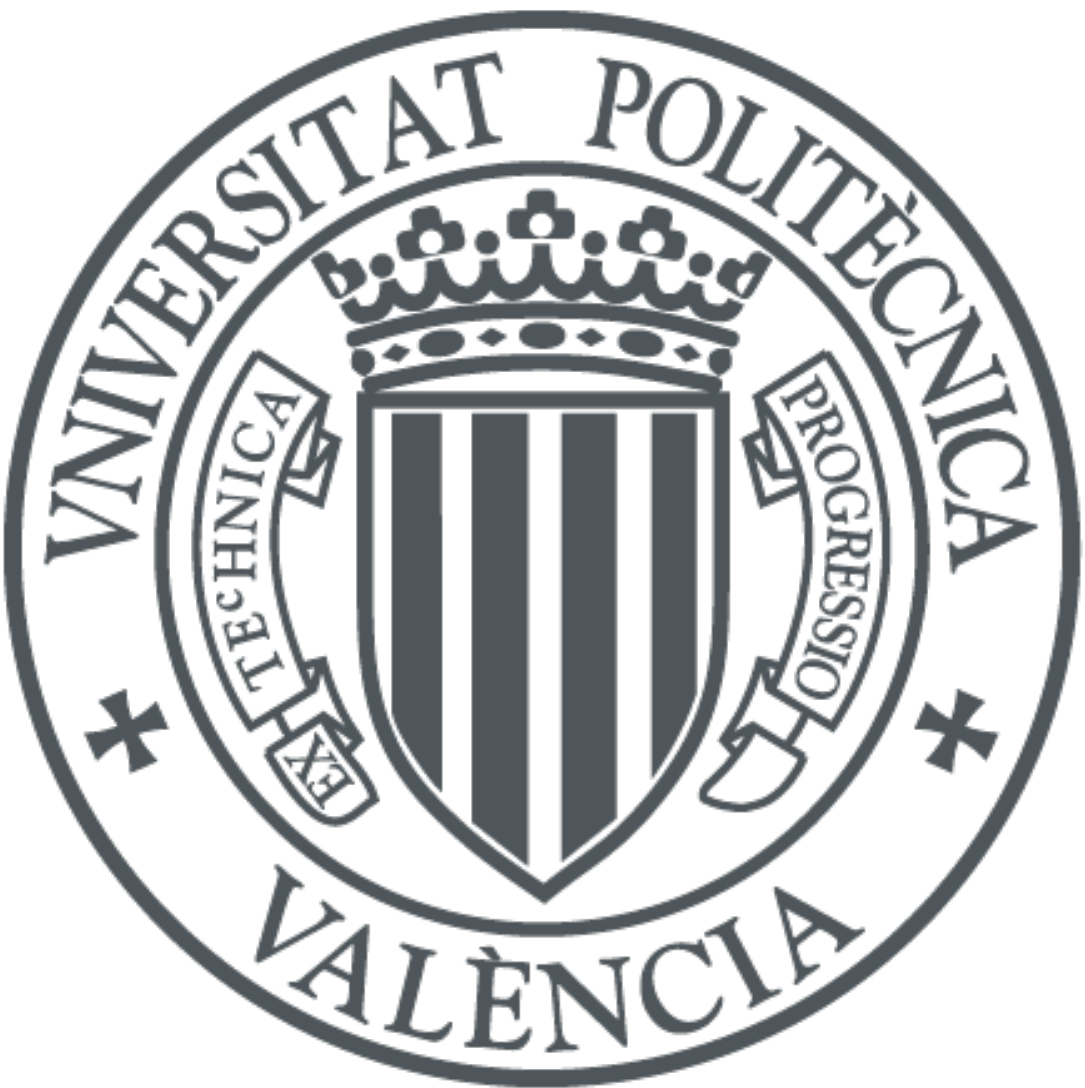

The final publication is available at

http://dx.doi.org/10.1039/c0pp00153h

Copyright Royal Society of Chemistry

Additional Information 


\section{Solar UV exposure of Primary Schoolchildren in Valencia, Spain.}

María-Antonia Serrano ${ }^{1 \star *}$, Javier Cañada ${ }^{2 \star}$, Juan Carlos Moreno ${ }^{1 \star}$

${ }^{1}$ Departamento de Física Aplicada, Universidad Politécnica de Valencia, 46022 Valencia, España

${ }^{2}$ Departamento de Termodinámica Aplicada, Universidad Politécnica de Valencia, 46022 Valencia, España

`Members of the Valencia Solar Radiation Research Group

*Corresponding author: mserranj@ fis.upv.es (Maria-Antonia Serrano). 


\begin{abstract}
To quantify schoolchildren's exposure to ultraviolet erythemal radiation (UVER), personal dosimeters (VioSpor) were used to measure biologically effective ultraviolet (UV) radiation received in the course of their daily school activities. The study took place in two primary schools in Valencia (39 $28^{\prime}$ N) Spain, for several weeks from March 2008 until May 2009, with two age groups (6-8 years and 10-11 years) and involved about 47 schoolchildren. The median daily UV exposure values for all age groups and solar height intervals considered in the study ranged from 1.31 to 2.11 standard erythemal doses (SEDs). Individual UV exposure was analyzed as a function of age, gender and dosimeter position. Significant statistical differences were found between different age groups, with the younger age group receiving higher statistically significant UVER exposure. It was also found that boys received significantly higher UVER exposure than girls. It was also noted that shoulder dosimeters registered higher readings than wrist dosimeters.

Exposure ratio (ER) is defined as the ratio between the personal dose on a selected anatomical site and the corresponding ambient dose on a horizontal plane. The median ER for all age groups and solar height intervals in the study range from $4.5 \%$ to $10.7 \%$, with higher values at lower solar heights.
\end{abstract}




\section{Introduction}

Exposure to UV radiation is considered to be one of the most important risk factors in the development of skin cancer. ${ }^{1-3}$ Schoolchildren receive regular and significant solar ultraviolet erythemal radiation (UVER) in their everyday activities, such as break periods spent outdoors and outdoor physical education classes. To quantify the children's exposure to UVER, sensitive spore-film filter-type personal dosimeters (VioSpor) were used to measure the biologically effective UV radiation received in the course of their activities during the spring, autumn and winter period in Valencia $\left(39^{\circ} 28^{\prime} \mathrm{N}\right)$ (Spain).

Many studies have measured UVER exposure in children and adolescents, as sunlight exposure is believed to be more crucial for the development of cutaneous melanoma during youth than in adults. ${ }^{3-6}$ It has also been estimated that $25 \%$ of an individual's cumulative lifetime UV exposure occurs before the age of 18 years ${ }^{7}$. A review of about 30 studies on exposure to solar ultraviolet radiation in young people has recently been published. ${ }^{8}$ Some of these studies on individual solar UVER exposure measured by personal dosimeter were carried out on schoolchildren ${ }^{8-16}$, although none have so far been conducted in Spain.

Although it is difficult to compare results from different studies, due to the different approaches and methods used, the Exposure Ratio (ER) was chosen to minimize the effects of season, latitude and time of day. ER is defined as the ratio between the personal dose on a selected anatomical site and the corresponding ambient dose on a horizontal plane during the same exposure period. Mean ER for primary schoolchildren on weekdays during summer tends to lie within a range from $2.8-4.5 \%$ in South Africa $^{8}, 6-7 \%$ in England ${ }^{10}$ and $4.6 \%$ in Australia $^{11}$. In Australia, weekday ER values range from 4.3 to $12.8 \%$ in early summer to late 
winter $^{12}$. From late spring to early autumn weekly ER was $2.8 \%$ in New Zealand. ${ }^{13}$ In Japan ${ }^{14}$, a $4 \%-9.9 \%$ average yearly UV exposure to ambient UV was measured and in Denmark ${ }^{15}$ it was $4.1 \%$ for children from 4-15 years old. Boldeman et al. ${ }^{16}$ studied the UVR exposure of Swedish preschool children (1-6 years) and obtained an average relative UVER exposure of $6.4 \%$ in late spring.

However, solar exposure also has beneficial effects on human health, such as the synthesis of Vitamin $\mathrm{D}^{17}$ required for skeletal health, important for children at the growing stage and has been suggested as having beneficial properties against breast and colon cancers in adulthood ${ }^{18}$. The aim of this work was to quantify the UVER exposure of primary schoolchildren in the course of several days in their daily schedules during the spring, autumn and winter period in Valencia (Spain).

Individual UV exposure was measured using sensitive spore-film filter-type personal dosimeters (VioSpor) and was analyzed as a function of age, gender and dosimeter position. Dosimeters can be used effectively for personal UV measurements in outdoor occupations ${ }^{19-21}$, recreational activities ${ }^{21-24}$ and school activities ${ }^{14,16,25}$. They are also easy to place and manage and have a spectral sensivity profile similar to erythema-weighted data calculated from spectral measurements.

\section{Materials and methods}

\subsection{Study location}

The study was performed in Valencia, Spain, (coordinates $0^{\circ} 22^{\prime} \mathrm{W}, 39^{\circ} 28^{\prime} \mathrm{N}$, sea level), in two primary schools at a distance of about 1 kilometre from each other. The periods included a winter campaign (2007-08), two spring campaigns (2008 and 2009) and an autumn-winter 
campaign (2008-09). In the school identified as E.P. there was only one group of children aged 6-8, whereas school P.C. included children from both age groups.

\subsection{Subjects and design}

Two groups of subjects were identified using similar age breakdowns to previous studies, such as Wright et al. ${ }^{13}$. The two age groups were 6-8 and 10-11 years old. Subject recruitment was done on a volunteer basis, and included written consent by the parents of the participating children. The first meeting was with the head teacher at each school to explain the requirements of the study. A subsequent meeting took place to inform teachers of the details of the study and to ask for volunteers to participate. The teachers compiled a diary in which they kept a record of the times when dosimeters were put on and taken off, the number of hours spent outdoors and the children's skin type. Since the aim of this work was to study the exposures on days of maximum solar radiation, they were instructed to take readings on cloudless days, when most of the sky was clear of clouds at the beginning of their working day. When they were not sure how to classify the conditions, they were instructed to contact the authors by phone. They were also instructed not to change their activities during the measurement sessions and to continue with their normal routines.

Most of children were skin type III (74\%) according to the Fitzpatrick's classification. ${ }^{26}$ The individual cumulative solar UVER exposure was measured by a VioSpor ${ }^{27}$ dosimeter Type II, changed every 1, 2 or 3 days, depending on the time of year. Dosimetry of ambient UVER was performed simultaneously in the weather station of the Technical School of Industrial Engineering of Valencia (TSIE), coinciding with the measurement sessions in the schools. Children wore the UVER dosimeters placed either on their shoulders or on the wrist 
throughout their school day from 9:00 a.m. to 17:00 p.m. The shoulder was chosen as it receives the highest UVER exposure to the body, other than the head, which is often protected by a hat or other cover. Approximately half of the children wore the dosimeters attached to Velcro straps on the wrist, which is considered the most practical and suitable anatomical site for measuring solar ultraviolet radiation exposure. ${ }^{24}$

Solar height was estimated at noon on each day of the entire measurement period. Days of similar solar height were then grouped together and gave three periods with median solar height values of $36.4^{\circ}, 54.7^{\circ}$ and $71.7^{\circ}$ for school P.C.; and $34.6^{\circ}, 55.6^{\circ}$ and $71.7^{\circ}$ for school E.P. These periods correspond to autumn-winter, early spring, and late spring, respectively. In this paper and tables these periods will be referred to hereinafter as Solar Height (S.H.) 1, 2 and 3 , respectively.

One dosimeter was used every day in the school E.P. in the months of April and May 2008, and in the school P.C. in March 2008. In this school, dosimeters were used every 2 days in the period of May 2008 for both age groups. In the remaining periods, dosimeters were used every 3 days. To compare the measures, it was got the daily dose calculated by dividing several days Viospor reading by the number of days used.

Table 1 shows the measurement dates and the corresponding median (with maximum and minimum in brackets) of solar height for each school and for each period of the study. Also is shown the number of children of each age group who participated in each sub-period of each solar height.

In the 10-11 years age group there are 10 children who participated throughout the study, two more children who participated in October 2008 to May 2009 (except only one in March 2009), three more 
children who participated only in March 2009, one more child participating in April and May 2009 and finally two more children who only attended in April, 2009.

In the 6-8 years age group of school P.C. there are 10 children who participated throughout the study except in March 2008 and April 2009. In March 2008 involved 10 children, who did not return to do so throughout the study. Three more children participated in October 2008 to April 2009 except in February 2009, one more child participated in October 2008 to January 2009, and two more children participating in February to May 2009 (except in April 2009). Finally one more child only attended in October and November 2008, another more only in October 2008, and another more only in January 2009.

In the 6-8 years age group of school E.P., there are 6 children who participated throughout the study. $\langle$ Table 1>

\subsection{Personal UVER dosimeters}

A UV sensitive spore-film filter system (VioSpor Blue Line Type II Dosimeter, Bio-Sense, Bornheim, Germany) ${ }^{27}$ was used as the UV dosimeter. Spore-film production (DNA repairdeficient strain of Bacillus subtilis) and the development of the films are described in some papers $^{25,28}$. The spore films are covered by a filter system with optical properties simulating the erythemal response of human skin in accordance with the CIE reference spectrum ${ }^{29}$, and mounted in waterproof casings with a diameter of $32 \mathrm{~mm}$. The units of solar erythemal exposure are given by the manufacturer as $\mathrm{J} / \mathrm{m}^{2}$ and minimal erythema dose (MED) for skin type II. One MED corresponds to $250 \mathrm{~J} / \mathrm{m}^{2}$ normalized to $298 \mathrm{~nm}$, the dose which causes erythema in non-tanned Caucasian skin (skin type II) with sharply defined edges $24 \mathrm{~h}$. after sun exposure. The measurement range of the dosimeter is from $10^{-3}$ to $10^{1} \mathrm{~W}_{\mathrm{CIE}} / \mathrm{m}^{2}$, corresponding to $0.05 \mathrm{MED} /$ hour and $1000 \mathrm{MED} /$ hour, respectively, where $\mathrm{W}_{\mathrm{CIE}} / \mathrm{m}^{2}$ corresponds to the 
erythemal irradiance in accordance with the CIE reference spectrum ${ }^{29}$. The working range used is, according to the manufacturer, $0.4-22$ MED (type II) and measurement error is $\pm 10 \%$. The response is independent of humidity and temperature from $-20^{\circ} \mathrm{C}$ to $50^{\circ} \mathrm{C}^{27}$.

The measurements were expressed as standard erythema dose (SED) ${ }^{30}$ of biologically effective ambient solar UV radiation, where 1 SED is defined as effective $100 \mathrm{~J} / \mathrm{m}^{2}$ when weighted with the CIE erythemal response function ${ }^{29}$.

\subsection{Ambient UVER exposure}

One Type II dosimeter was set up on a horizontal plate at intervals of several days to measure UV radiation, coinciding with the readings taken from the subjects. The dosimeters were located on the roof of the TSIE station (coordinates $0^{\circ} 20^{\prime} 18^{\prime \prime} \mathrm{W}, 39^{\circ} 28^{\prime} 49^{\prime \prime} \mathrm{N}, 15 \mathrm{~m}$ above sea level) in the campus of the Polytechnic University of Valencia, to the north of the city of Valencia, far from industrial areas, near open country and approximately $1 \mathrm{~km}$ from the schools where the study took place. We used 31 dosimeters located on the roof an all did function. The dosimeters were controlled daily by an investigator of the paper. They were set and remove every day at the same time. They had no influence of adjacent buildings, and therefore all measurements have been good. Other available ambient UVER readings were from a YES UVB-1 radiometer, belonging to the Valencia Government's (GV) UVB measurement network ${ }^{31}$, located at $00^{\circ} 20^{\prime} 09^{\prime \prime} \mathrm{W} 39^{\circ} 27^{\prime} 49 \mathrm{~N}$, on the flat roof without obstructions or shade of a building in the city of Valencia, approximately 2 $\mathrm{km}$ from the University.

\subsection{Statistical analysis}

Data were analyzed using the Statgraphics Plus software v5.1 statistical package and are expressed as the median (25,75 percentile). The coefficient of variation (CV), a normalized 
measure of dispersion of a probability distribution, was also calculated to study if children behave as a homogeneous group. It is defined as the ratio of the standard deviation to the mean.

The Contrast W Mann-Whitney test (Wilcoxon) was used to compare differences between two samples in terms of UVER doses, ER or SED per hour outdoors. The Kruskall-Wallis test was used to compare differences between more than two groups in the same terms. Statistical significance was set at $\mathrm{p} \leq 0.05$ for all analyses.

\section{Results}

\subsection{Ambient solar UVER}

Actual temperature data provided by the State Agency for Meteorology ${ }^{32}$ for the entire period of the study is shown in Table 2, also ozone data obtained from an Ozone Monitoring Instrument (OMI, NASA) $)^{33}$ and the UV index (UVI) ${ }^{34,35}$ from the ambient UVER (SEDs) from the YES UVB-1 radiometer belonging to the Generalitat of Valencia station. As can be seen from the table, solar UVI is low in the winter period (2-3) and quite high (between 7 and 8) in the spring, both normal for the time of year in Valencia. The total column ozone from the OMI measurements for Valencia varies from 268 D. U. on 13 October, 2008 to 413 D.U. on 5 March, 2008.

$<$ Table 2>

\subsection{Measured UVER exposures}

Table 3 shows the number of dosimeters used and mean time outdoors per day, total exposure by gender and dosimeter position, for each school, age group and period of the study. 
We were able to analyse 372 dosimeters and only 10 were out of range of the sensitivity of the dosimeter. The children comply well and the teachers completed a daily diary with the information requested by researchers. Of the total of 372 dosimeters analyzed, only 4 had a measured dose less than $2 \%$ of its respective calculated maximum potential dose $^{10}$.

$<$ Table 3>

3.2.1 6-8 year group. Tables 4 and 5 show the median $(25,75$ percentile) daily measured dosimeter exposures in SEDs for the 6-8 year group for each of the solar height intervals, with the highest value of $2.11(1.45,2.73)$ SEDs for S.H. 3. Also given is a summary of the median ambient UVER as measured by the dosimeters, in SEDs, and the children's median $(25,75$ percentile) outdoor UV exposure, in SED per hour $(0.80(0.59,1.14)$ for $\mathrm{S}$. $\mathrm{H}$. 3). Also interesting is the fraction of ambient radiation subjects were exposed to, ranging from $10.7 \%$ for S.H. 1 to $6.1 \%$ for S. H. 3. The results discussed above are subclassified by gender in Table 4 and by dosimeter position in Table 5. The median daily UVER exposure received by boys was significantly higher than by girls (2.00 against 1.45 SEDs, $\mathrm{p}=0.0004)$, as was ER (9.2\% against $6.3 \%, \mathrm{p}=2 \mathrm{E}-5)$. UVER exposure received by the shoulder dosimeters was also significantly higher than those placed on the wrist ((1.91 against 1.53 SEDs, $p=0.005)$. The median daily UVER exposure and ER received by children in the S.H. 1 period is significantly lower to that received in the other two periods ( $\mathrm{p}=2 \mathrm{E}-5$, Kruskall-Wallis test).

$<$ Table 4>

$<$ Table 5>

3.2.2 10-11 year group. Tables 6 and 7 show the median $(25,75$ percentile $)$ daily measured dosimeter exposures in SEDs for the 10-11 year group for each of the solar height intervals, with the highest value of $1.81(1.13,2.18)$ SEDs for S.H. 2. The median ambient 
UVER as measured by the dosimeters is also shown in SEDs and the children's median $(25,75$ percentile) outdoor UV exposure, in SED per hour, with the highest value of $0.55(0.34,0.75)$ for S. H. 2. Also interesting is the ER, ranging from $10.1 \%$ for S.H. 1 to $4.5 \%$ for S. H. 3. The results discussed above are subclassified by gender in Table 6 and by dosimeter position in Table 7. The UVER exposure received by boys was significantly higher than by girls (4.73 against 3.86 SEDs, $\mathrm{p}=0.036)$, as was ER (9.0\% against $7.1 \%, \mathrm{p}=0.037)$, while no significant difference was found regarding the dosimeter position $(\mathrm{p}=0.60)$. The median daily UVER exposure received by children in the S.H. 1 period is significantly lower than that received in the other two periods ( $\mathrm{p}=0.003$, Kruskall-Wallis test), while ER is significantly different in all three periods ( $\mathrm{p}=1 \mathrm{E}-5$, Kruskall-Wallis test).

$<$ Table 6>

$<$ Table 7>

\subsubsection{Comparison of all subjects.}

Significant statistical differences were found between boys and girls, with boys receiving significantly higher UVER exposure than girls (considered as outdoor SED per hour, 0.67 against 0.52 , $\mathrm{p}=2 \mathrm{E}-4$, or SED per day, 1.88 against $1.43, \mathrm{p}=2 \mathrm{E}-4)$ as was $\mathrm{ER}(8.6 \%$ against $6.1 \%, \mathrm{p}=2 \mathrm{E}-5)$. Using the same analysis for shoulder and wrist dosimeters, those placed on the shoulder received significantly higher UVER exposure ( $\mathrm{p}=0.006,0.62$ against 0.53 SED per hour outdoor), while no significant difference was found regarding the ER (8\% against $7.3 \%$, $\mathrm{p}=0.12)$.

Significant differences were found between the two age groups, with the younger children receiving significantly higher UVER exposure than the older ones, analyzed as SEDs per day (1.77 against 1.51 SEDs, $\mathrm{p}=0.018$ ) or analyzed as SED per hour outdoor (0.67 against 0.47 , 
$\mathrm{p}=2 \mathrm{E}-7)$ ). However, no significant difference was found in $\mathrm{ER}(\mathrm{p}=0.33)$. When subclassified by gender, we did not find any significant differences in SED per day and ER between boys $(\mathrm{p}=0.08, \mathrm{p}=0.09)$ in the two different age groups or for girls $(\mathrm{p}=0.45, \mathrm{p}=0.83)$ in the two different age groups. However, a significant difference was found for outdoor SED per hour in boys of the two different age groups $(0.72$ against $0.51, p=8 \mathrm{E}-4)$ and also in the two girls' groups ( 0.57 against $0.45, \mathrm{p}=0.007)$, the younger children receiving the highest values. When we considered dosimeter position, we found that there were no significant differences between subjects with wrist dosimeters in both age groups as to SED per day ( $\mathrm{p}=0.43)$, unlike outdoor SED per hour (0.58 against $0.44, \mathrm{p}=8 \mathrm{E}-4)$. Those with shoulder dosimeters received significantly higher UVER exposure in the lower age group (1.91 against 1.51 SEDs per day, $\mathrm{p}=0.013)$, or analyzed as SED per hour outdoor $(0.71$ against $0.50, \mathrm{p}=4 \mathrm{E}-4)$.

When considering solar height, we noticed that the median daily UVER exposure received by all children in the S. H. 1 period is significantly lower than those received in the other two periods ( $\mathrm{p}=1.4 \mathrm{E}-7$, Kruskall-Wallis test). For ER, the three periods are all significantly different ( $\mathrm{p}=1 \mathrm{E}-5$, Kruskall-Wallis test).

3.2.4 Comparison of 6-8 year old children from 2 schools. The results presented can not draw conclusions as compared many children from school P.C. with only 6 children from school E.P. Anyway, it has made a statistical study following the previous models, but without differentiating by sex or position of the dosimeter.

No statistically significant differences were found in regard to median outdoor UV exposure per hour between the 6-8 year-old children either between schools $(\mathrm{p}=0.189)$ When we considered ER, we found that P.C. schoolchildren had significantly higher ER than those of the 
other school (8.3\% against 7.2\%, p=0.028). For S.H.1, P.C schoolchildren had significantly higher ER ( $p=0.002)$, whereas for S.H. 3, E.P. schoolchildren had significantly higher ER $(\mathrm{p}=0.023)$.

\subsubsection{Homogeneity of exposure.}

For every school and age group, the $\mathrm{CV}$ was calculated to study if children behave as a homogeneous group with respect to outdoor UVER exposure. Since the CVs obtained for the two groups of 6 years old and the group of 10 years old, are above $50 \%$, we conclude that some children, day on day, received consistently higher or lower exposures than their classmates.

\section{Discussion}

It is difficult to compare results of studies on UV exposure in children due to the difference in their design, such as anatomical dosimeter position and type, latitude, season and age group. For this reason, ER was chosen to minimize the effects of season, latitude and time of day on the analysis.

The measurements days in school P.C. for the two age groups are the same, except in the sub-period April 2009 due to organizational problems on April 1, 2009 by the group of 6 years old. Since the days of measurements at school E.P. are not the same, but similar, ER was chosen to compare results.

The results of this study are moderately consistent with those of Guy et al. ${ }^{8}$, who found $4.5 \%$ ambient UVER exposure for 4-6 year-olds and 2.8\% for 7-9 year-olds on the clavicle, during summer in South Africa. In our study, using schoolchildren with dosimeters on the shoulder, we obtained 5.5-6.9 \% for 6-8 year-olds and $4.5 \%$ for $10-11$ year-olds in late spring. Diffey et al. ${ }^{10}$ 
found that 9-10 year-old English schoolchildren received 6-7\% ambient UVER exposures on the chest in summer, similar to our results for shoulder exposure in this age group. In Australia, Kimlin et al. ${ }^{11}$ found about $4.6 \%$ ambient UVER exposure for 8 year-old schoolchildren on the shoulder during late summer and Gies et al. ${ }^{12}$ recorded 5-8\% ambient UVER exposure in summer and $4-8 \%$ in winter for 12 year-olds on the shoulder. Our result for autumn-winter in 10-11 yearolds was $10.1 \%$ in a slightly higher position. Wright et al. ${ }^{13}$ measured $5.8 \%$ ambient UVER from late spring to early autumn in New Zealand for two age groups (8 and 12 years old). In Japan, Ono et al. ${ }^{14}$ obtained a yearly average of UV exposure to ambient UV of $4 \%$ to $9.9 \%$ on the upper arm, including weekends, for 8-9 year-old schoolchildren. While we measured only during school attendance days, our median annual shoulder percentage for the 10-11 age group was $8.5 \%$. In Denmark $^{15} 4.1 \%$ annual ambient UVER was measured on the wrist of 4-15 year-old children, results slightly lower than ours, $7.7 \%$ ambient UVER for both age groups in the same dosimeter position. Boldeman et al. ${ }^{16}$ studied the shoulder UVER exposure of Swedish preschool children (1-6 years) and obtained an average $6.4 \%$ relative UVER exposure in late spring. Our results gave 5.5-6.9\% ambient UVER for the 6-8 year-old group with identical dosimeter position and period. Diffey et al. ${ }^{10}$ and Thieden et al. ${ }^{15}$ have experienced that some persons day after day get higher respectively lower UV doses than their peers. In our study, the CV was calculated to study if children behave as a homogeneous group with respect to outdoor UVER exposure. Since this coefficient obtained for all groups is above $50 \%$, we conclude that, in fact, some children, day on day, received consistently higher or lower exposures than their classmates.

It can be seen in Table 1 that school E.P. had the same groups participate at different times of the year, when the ambient solar UVER was different, so we can compare this group's UVER exposures at these different times. UVER exposure is generally proportional to ambient, so when 
the UVER ambient is higher, the same group receives higher UVER exposure as can be seen in Table 4.

When we compared all the children by gender, significant statistical differences were found, with boys receiving significantly higher UVER exposure than girls. These results are consistent with other studies. ${ }^{9,10,12}$ Using the same analysis for shoulder and wrist dosimeters, we found that the shoulder received significantly higher UVER exposure, in agreement with other studies on outdoor activities. ${ }^{36,37}$ If we considerer the solar height, UVER exposure received by all children in the S.H. 1 period is significantly lower than that received in the other two periods. The three periods have significantly different ER values (Kruskall-Wallis test). ER is greater in winter than in late spring (10.7\% against $6.1 \%)$, probably due to the children seeking the shade in the months of highest solar radiation and seeking solar radiation in the winter months. Another reason may be that due to the lower solar altitude resulting in higher relative amounts of diffuse UV. Although median ER is higher in winter, the schoolchildren's UVER exposure is higher in late spring, due to higher ambient UVER in this season.

When we compared the two age groups, we found that the younger children received significantly higher UVER exposure than the older ones. This could be due to increased awareness of the dangers of excessive solar radiation in older children. The same did not happen when we compared ER for the same groups, probably owing to the fact that the days of measurement of both age groups were not the same, so neither the ambient UVER for ER calculation.

We also compared 6-8 year old children from the two different schools, although we can not draw definitive conclusions as compared many children from school P.C. with only 6 
children from school E.P.. We did not find statistically significant differences in regard to UVER exposure. When we considered ER, we found statistically significant differences between ER in the two schools for each solar height interval. The school E.P. group gets approximately half the dose of the group P.C. at S. H. 1. This is due to the architectural conditions and conditions of the buildings in the two schools. In the school E.P., there is a building south solar that produce shadow in the school yard when the solar height is small, while when the solar height is higher this shadow disappears. Also, probably is owing to the fact that, as said before, the readings for each group were taken on different days, as can be seen in Table 1. The schoolchildren E.P. received higher doses at S.H. 2 and S.H. 3, in addition to the architectural conditions, because they are more time outdoors, as shown in Table 3.

The other school (P.C.) has trees and shadow structures, and when the day is hot, children are protected in the shade, while in the school E.P. the school yard has not trees or shadow structures.

When we considered the period with the highest solar radiation in our study (S.H. 3), median daily UV exposure classified by gender was about $2.39(1.70,3.43)$ SEDs for boys and $1.76(1.28,2.29)$ SEDs for girls; when classified by dosimeter position was $2.11(1.38,2.98)$ SEDs for the shoulder and $1.76(1.10,2.58)$ SEDs for the wrist, and by age group was 2.11 $(1.45,2.73)$ SEDs and $1.70(1.09,2.65)$ SEDs for the 6-8 and 10-11 age groups, respectively. Therefore, in regard to age group, this exposure exceeded 1 SED by a factor of 2.1 and 1.7 respectively, so that the children received approximately 2 times the expected UVER load for unprotected skin and eyes in their daily outdoor activities in late spring, indicating that protective measures are necessary, with the boys from the 6-8 age group receiving far more radiation (2.61 SEDs per day in late spring). 
Although children spend up to 3-4 h per day exposed to UV radiation, it is possible for this population to partially avoid UV exposure, especially in the summer, by seeking the shade of trees, buildings, etc. The use of sunscreens and protective clothing are advisable protective strategies.

The recommendations for UV minimisation based on this research would be targeted at those responsible for the design and construction of schools, to take into consideration to increase the number of trees and shade structures, and so to increase the amount of shade. Thus, students could enjoy recreational spaces without receiving much solar radiation.

This information has been sent to the heads of the schools so that, within its capabilities, take action to reduce the level of radiation received by the children.

In conclusion, a personal VioSpor film dosimeter was used to measure the UV exposure of primary schoolchildren at school, who were found to far exceed international UV exposure limits. These high exposure values are suggestive of an increased risk of skin cancer, as sunlight exposure is believed to be more crucial for the development of cutaneous melanoma during youth than as an adult.

\section{Acknowledgments}

The authors wish to thank the teachers and children of the schools for their cooperation in this study. We are also grateful to the State Agency for Meteorology and the Generalitat Valenciana for providing us with access to their meteorological data.

We would like to thank the R\&D\&I Linguistic Assistance Office, Universidad Politécnica de Valencia (Spain), for granting financial support for the proof-reading of this paper. 
The research reported here was supported by the Spanish Ministry of Education and Science within the research project CGL2007-61813. 


\section{References}

1 IARC, IARC monographs on the evaluation of carcinogenic risks to humans: solar and ultraviolet radiation, Lyon, 2000, 55.

2 B.K. Armstrong, and A. Kricker, The epidemiology of UV induced skin cancer, J. Photochem. Photobiol. B, 2001, 63, $8-18$.

3 B. Armstrong, How sun exposure causes skin cancer: an epidemiological perspective. In Prevention of Skin Cancer, ed by D. Hill, J. M. Elwood and D. R. English, Kluwer Academic, 2005, pp. 89-116.

4 A. Østerlind, M.A. Tucker, B.J. Stone and O.M. Jensen, The Danish Case Control Study of cutaneous malignant melanoma. II. Importance of UV-light exposure, Int J Cancer, 1988, 42, $319-324$.

5 M.A. Weinstock, G. A. Colditz, W. C. Willet, M. J. Stampfer, B. R.Bronstein, M. C. Mihm, Jr., and F. E. Speizer, Non-familial cutaneous melanoma incidence in women associated with sun exposure before 20 years of age, Pediatrics, 1989, 84, 199-204.

6 S.A.Oliveria, M. Saraiya, A. C. Geller, M. K. Heneghan and C. Jorgensen, Sun exposure and risk of melanoma, Arch. Dis. Child., 2006, 91, 131-138. 
7 M. Saraiya, K. Glanz, P. A. Briss, P. Nichols, C. White, D. Das, S. J. Smith, B. Tannor, A. B. Hutchinson, K. M. Wilson, N. Ghandi, N. C. Lee, B. Rimer, R. C. Coates, J. F. Kerner, R. A. Hiatt, P. Buffler and P. Rochester, Interventions to prevent skin cancer by reducing exposure to ultraviolet radiation: a systematic review, Am. J. Prev. Med., 2004, 27, 422-466.

8 C. Wright, and A. Reeder, Youth solar ultraviolet radiation exposure, concurrent activities and sun-protective practices: A review, Photochem. Photobiol., 2005, 81, 1331-1342.

9 C.Y. Guy, R. D. Diab and B. M. Martincigh, Ultraviolet radiation exposure of children and adolescents in Durban, South Africa, Photochem. Photobiol., 2003, 77, 265-270.

10 B.L. Diffey, C. J. Gibson, R. Haylock and A. F. McKinlay, Outdoor ultraviolet exposure of children and adolescents, Br. J. Dermatol., 1996, 134, 1030-1034.

11 M. Kimlin, and A. Parisi, Usage of real-time ultraviolet radiation data to modify the daily erythemal exposure of primary schoolchildren, Photodermatol. Photoimmunol. Photomed., 2001, 17, 130-135.

12 P. Gies, C. Roy, S. Toomey, R. MacLennan and M. Watson, Solar UVR exposures of primary schoolchildren at three locations in Queensland, Photochem. Photobiol., 1998, 68, 78-83.

13 C.Y. Wright, Reeder AI, Bodeker GE, Gray A, Cox B., Solar UVR exposure, concurrent activities and sun-protective practices among primary schoolchildren, Photochem. Photobiol., 
2007, 83, 749-758.

14 M. Ono, N. Munakata and S. Watanabe, UV exposure of elementary school children in five Japanese cities, Photochem. Photobiol., 2005, 81, 437-445.

15 E.P. Thieden, A. Philipsen, J. Heydenreich and H. C. Wulf, UV radiation exposure related to age, sex, occupation, and sun behaviour based on time-stamped personal dosimeter readings, Arch. Dermatol., 2004, 140, 197-203.

16 C. Boldeman, H. Dal and U. Wester, Swedish pre-school children's UVR exposure - a comparison between two outdoor environments, Photodermatol. Photoimmunol. Photomed., 2004, 20, 2-8.

17 M. Norval, M., A.P.Cullen, F.R. de Gruijl , J. Longstreth, Y. Takizawa, R.M. Lucas, F.P. Noonan and J.C. van der Leun J. C., The effects on human health from stratospheric ozone depletion and its interactions with climate change, Photochem. Photobio.l Sci., 2007, 6, 232251.

18 W.B. Grant and M.F. Holick, Benefits and requirements of vitamin D for optimal health: a review, Alternative Medicine Review, 2005, 10(2), 94-104.

19 M. Moehrle, M. Korn and C. Garbe, Bacillus subtilis spore film dosimeters in personal dosimetry for occupational solar ultraviolet exposure, Int. Arch. Occup. Environ. Health, 2003, 
$173,575-580$.

20 M. Moehrle, B. Dennenmoser and C. Garbe, Continuous long-term monitoring of UV radiation in Professional mountain guides reveals extremely high exposure, Int. J. Cancer, 2003, 103, $775-778$.

21 M. Moehrle, and C. Garbe, Personal UV dosymetry by Bacillus subtilis Spore Films, Dermatology, 2000, 200, 1-5.

22 M. Moehrle, L. Heinrich, A. Schmid and C. Garbe, Extreme UV exposure of professional Cyclists, Dermatology, 2000, 201, 44-45.

23 M. Moehrle, Ultraviolet exposure in the Ironman triathlon, Off. J. of the Amer. Coll. of Sports medicine, 2000, 33(8), 1385-1386.

24 E. Thieden, M. S. Ågren and H. C. Wulf, The wrist is a reliable body site for personal dosimetry of ultraviolet radiation, Photodermatol. Photoimmunol. Photomed., 2000, 16, 57-61.

25 N. Munakata, M. Ono and S. Watanabe, Monitoring of Solar-UV Exposure among Schoolchildren in Five Japanese Cities using Spore Dosimeter and UV-coloring Labels, Jpn. J. Cancer Res., 1998, 89, 235-245.

26 T.B. Fitzpatrick, M. Pathak and J. A. Parrish, Protection of human skin against the effects of 
the sunburn ultraviolet (290- $320 \mathrm{~nm})$. In Sunlight and Man: Normal and Abnormal Photobiologic Responses, ed. by M. A. Pathak, L. C. Harber, M. Seiji and A. Kukita, University of Tokyo Press, Tokyo, 1974, p. 751.

27 Biosense Laboratories, Available at www.biosense.de/home-e.htm, Accessed on 5 March 2010.

28 Y. Furusawa, L.E. Quintern, H. Holtschmidt, P. Koepke and M. Saito, Determination of erythema-effective solar radiation in Japan and Germany with a spore monolayer film optimized for the detection of UVA and UVA - results of a field campaign, Appl. Microbiol. Biotechnol., 1998, 50, 597-603.

29 A.F. McKinlay, and B.L. Diffey, A reference action spectrum for ultraviolet induced erythema in human skin, CIE Journal, 1987, 6, 17-22.

30 The International Commission on Illumination, Standard Erythema Dose, a Review, CIE Journal 125, Vienna, 1997.

31 Programa meteorología de la Fundación Centro de Estudios Ambientales del Mediterráneo (Generalitat Valenciana), Available at http://www.gva.es/ceamet/vigilancia/radUV/radUV.html, Accessed on 10 March 2010.

32 Agencia Estatal de Meteorología, Available at http://www.aemet.es/, Accessed on 10 March 2010. 
33 NASA, Total Ozone Mapping Spectrometer, Available at http://jwocky.gsfc.nasa.gov/, Accessed on 10 March 2010.

34 World Health Organization, Global Solar UV Index: A Practical guide, WHO, Geneva, Switzerland, 2002.

35 International Commission on Non-Ionizing Radiation Protection, Global Solar UV Index, ICNIRP-1/95, 1995.

36 E. Herlihy, H. P. Gies, C. R. Roy and M. Jones, Personal dosimetry of solar UVR for different outdoor activities, Photochem. Photobiol., 1994, 60, 288-294.

37 C.D.J. Holman, I. M. Gibson, M. Stephenson and B. K. Armstrong, Ultraviolet irradiation of human body sites in relation to occupation and outdoor activity: field studies using personal UVR dosimeters, Clin. Exp. Dermatol., 1983, 8, 269-277. 
Table 1. Measurement dates for each school, corresponding median solar height (with maximum and minimum in brackets) of each period of the study and number of children who participated in the study in each age group and period.

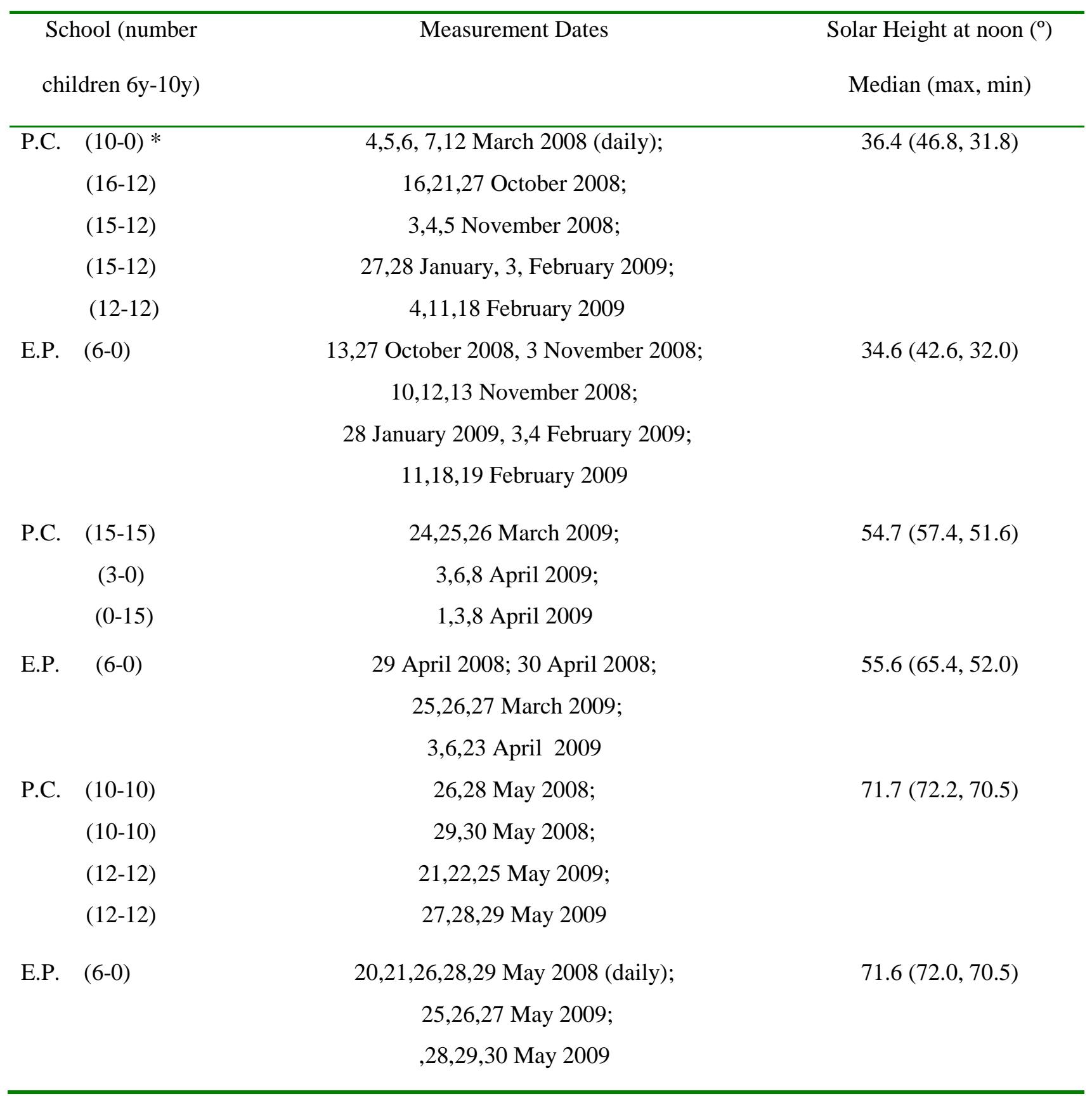

*School name and, in brackets, the first number is the number of children in 6-8 year age group, second number is the number of children in 10-11 year age group. 
Table 2. Actual Mean temperature (with maximum and minimum in brackets) of the indicated period, maximum and minimum of ozone concentration from Ozone Monitoring Instrument (NASA) for the indicated period, maximum and minimum ambient UVER and UV index (from the UVER (SEDs) from YES UVB-1 radiometer at the Generalitat of Valencia station) for the indicated period.

\begin{tabular}{|c|c|c|c|c|}
\hline Date & $\begin{array}{c}\text { Air temperature } \\
\left({ }^{\circ} \mathrm{C}\right)\end{array}$ & $\begin{array}{c}\text { Ozone } \\
\text { (Dobson Units) }\end{array}$ & $\begin{array}{c}\text { Ambient UVER } \\
\text { (SEDs) }\end{array}$ & UVI \\
\hline $4-7 / 03 / 2008$ & $10.4(18.8-4.9)$ & $322-413$ & $12.19-14.87$ & 3 \\
\hline $12 / 03 / 2008$ & $17.8(23.5-14.4)$ & 297 & 21.65 & 5 \\
\hline $29,30 / 04 / 2008$ & $17.3(22.9-12.4)$ & $337-342$ & $35.48-37.28$ & 7 \\
\hline $20,21 / 05 / 2008$ & $19.7(28-14.0)$ & 365 & $39.35-40.66$ & $7-8$ \\
\hline $26,28-30 / 05 / 2008$ & $19.6(26.9-15.0)$ & $334-359$ & $28.44-44.55$ & $7-8$ \\
\hline $13,16,21,27 / 10 / 2008$ & $20.7(24.5-13.8)$ & 256-292 & $12.30-15.28$ & 3 \\
\hline $3-5 / 11 / 2008$ & $13.8(19.5-8.0)$ & $326-350$ & $8.44-10.52$ & 2 \\
\hline $10,12,13 / 11 / 2008$ & $14.5(19.0-10.2)$ & $288-308$ & $6.93-9.84$ & 2 \\
\hline $27,28 / 01 / 2009$ & $13.9(20.5-9.5)$ & $303-335$ & $6.61-7.08$ & 2 \\
\hline $3,4 / 02 / 2009$ & $11.9(18.0-7.9)$ & 366 & $8.66-11.22$ & $2-3$ \\
\hline $11,18,19 / 02 / 2009$ & $11.2(20.2-5.5)$ & $354-359$ & $11.26-12.54$ & 3 \\
\hline $24-27 / 03 / 2009$ & $14.0(21.4-8.1)$ & $327-351$ & $23.73-26.23$ & 5 \\
\hline $1,3,6,8 / 04 / 2009$ & $13.3(17.8-8.1)$ & $382-399$ & $20.76-24.90$ & 7 \\
\hline $23 / 04 / 2009$ & $18.5(25.5-12.8)$ & 331 & 42.25 & 8 \\
\hline $21,22 / 05 / 2009$ & $19.1(22.0-16.9)$ & 306 & $26.80-44.02$ & $6-9$ \\
\hline $25-29 / 05 / 2009$ & $20.8(25.8-15.1)$ & $331-345$ & $42.65-48.16$ & 8 \\
\hline
\end{tabular}


Table 3. Number of dosimeters used mean time spent outdoors by age and gender, and dosimeter position by school and period of the study.

\begin{tabular}{|c|c|c|c|c|c|c|c|}
\hline & \multirow[b]{2}{*}{ Age } & \multirow[b]{2}{*}{$\begin{array}{c}\text { Mean Time } \\
\text { outdoors/day } \\
\text { (h.) }\end{array}$} & \multicolumn{5}{|c|}{ Number of DOSIMETERS (Mean time outdoors/day) } \\
\hline & & & Total & girls & boys & wrist & shoulder \\
\hline \multicolumn{8}{|c|}{ Solar Height $1^{*}$} \\
\hline \multirow[t]{2}{*}{ School P.C. } & $6-8 y$ & 2.89 & 104 & $40(2.70 \mathrm{~h})^{\bullet}$ & $64(3.00 h)$ & $52(2.88 \mathrm{~h})$ & $52(2.90 \mathrm{~h})$ \\
\hline & $10-11 y$ & 3.20 & 47 & $27(3.19 \mathrm{~h})$ & $20(3.22 h)$ & $25(3.22 h)$ & $22(3.19 \mathrm{~h})$ \\
\hline School E.P. & $6-8 y$ & 2.17 & 22 & $10(1.95 \mathrm{~h})$ & $12(2.36 \mathrm{~h})$ & $10(1.95 \mathrm{~h})$ & $12(2.36 \mathrm{~h})$ \\
\hline \multicolumn{8}{|c|}{ Solar Height 2} \\
\hline \multirow[t]{2}{*}{ School P.C. } & $6-8 y$ & 2.16 & 18 & $8(2.04 h)$ & $10(2.26 h)$ & $9(2.03 \mathrm{~h})$ & $9(2.29 \mathrm{~h})$ \\
\hline & $10-11 y$ & 3.26 & 30 & $15(3.18 \mathrm{~h})$ & $15(3.33 h)$ & $15(3.50 \mathrm{~h})$ & $15(3.02 \mathrm{~h})$ \\
\hline School E.P. & $6-8 y$ & 2.74 & 24 & $12(2.61 \mathrm{~h})$ & $12(2.86 h)$ & $12(2.61 \mathrm{~h})$ & $12(2.86 h)$ \\
\hline \multicolumn{8}{|c|}{ Solar Height 3} \\
\hline \multirow[t]{2}{*}{ School P.C. } & $6-8 y$ & 2.55 & 44 & $24(2.60 \mathrm{~h})$ & $20(2.50 \mathrm{~h})$ & $22(2.50 \mathrm{~h})$ & $22(2.61 \mathrm{~h})$ \\
\hline & $10-11 y$ & 3.30 & 43 & $28(3.31 \mathrm{~h})$ & $15(3.28 \mathrm{~h})$ & $22(3.51 \mathrm{~h})$ & $21(3.32 h)$ \\
\hline School E.P. & $6-8 y$ & 2.94 & 40 & 19 (2.93h) & $21(2.94 h)$ & $4(3.00 \mathrm{~h})$ & $36(2.93 \mathrm{~h})$ \\
\hline
\end{tabular}

\footnotetext{
* Solar Heights 1,2 an 3 correspond to the periods whose median values of solar height are $36.4^{\circ}, 54.7^{\circ}$ and $71.7^{\circ}$ for school P.C.; and $34.6^{\circ}, 55.6^{\circ}$ and $71.7^{\circ}$ for school E.P, respectively.

- Number of dosimeters used corresponding to girls in 6-8 year group at School P.C. In brackets, mean time spent outdoors per day for this girls' age group.
} 
Table 4. UVER exposure and ambient UVER (both given in SEDs) per day, measured using VioSpor dosimeters, and Exposure ratio for each of the solar height intervals, for 6-8 age group, stratified by sex.

\begin{tabular}{|c|c|c|c|c|}
\hline & UVER exposure & SED/Hour Outdoor & Median & Exposure Ratio \\
\hline & Median (25,75 percentile) & Median $(25,75$ & Ambient UVER & Median $(25,75$ \\
\hline & (SEDs) & percentile) & (SEDs) & percentile) $(\%)$ \\
\hline \multicolumn{5}{|l|}{ Solar Height 1} \\
\hline School P.C. girls & $1.17(0.78,1.73)$ & $0.51(0.32,0.61)$ & 13.02 & $8.6(5.9,13.4)$ \\
\hline School P.C. boys & $1.98(1.14,2.62)$ & $0.61(0.43,0.80)$ & 12.84 & $13.3(8.5,20.3)$ \\
\hline School E.P. girls & $0.53(0.41-0.90)$ & $0.33(0.19,0.58)$ & 11.90 & $5.0(3.1,7.7)$ \\
\hline School E.P. boys & $1.08(0.66,1.38)$ & $0.43(0.31,0.59)$ & 11.90 & $7.9(5.9,13.2)$ \\
\hline Total for S. H. 1 & $1.33(0.88,2.18)$ & $0.57(0.37,0.73)$ & 12.84 & $10.7(6.8,17.4)$ \\
\hline \multicolumn{5}{|l|}{ Solar Height 2} \\
\hline School P.C. girls & $0.98(0.62,1.74)$ & $0.45(0.36,0.95)$ & 24.88 & $3.9(2.5,7.0)$ \\
\hline School P.C. boys & $1.93(1.86,2.51)$ & $0.84(0.72,1.26)$ & 24.88 & $7.7(7.5,10.1)$ \\
\hline School E.P. girls & $2.25(1.40,2.76)$ & $0.77(0.66,0.96)$ & 27.14 & $8.2(4.8,10.3)$ \\
\hline School E.P. boys & $2.38(1.42,3.61)$ & $0.84(0.53,1.20)$ & 27.14 & $8.9(5.5,13.3)$ \\
\hline Total for S. H. 2 & $1.93(1.15,2.85)$ & $0.76(0.54,1.16)$ & 25.28 & $7.6(4.6,10.8)$ \\
\hline \multicolumn{5}{|l|}{ Solar Height 3} \\
\hline School P.C. girls & $1.73(1.34,2.29)$ & $0.75(0.51,1.14)$ & 36.11 & $4.3(3.4,6.9)$ \\
\hline School P.C. boys & $2.01(1.59,2.93)$ & $0.96(0.69,1.12)$ & 36.11 & $6.3(4.6,7.4)$ \\
\hline School E.P. girls & $2.11(1.78,2.99)$ & $0.70(0.59,1.00)$ & 29.25 & $6.1(4.4,8.7)$ \\
\hline School E.P. boys & $2.61(2.12,3.46)$ & $0.91(0.74,1.15)$ & 29.25 & $7.2(5.9,10.7)$ \\
\hline Total for S. H. 3 & $2.11(1.45,2.73)$ & $0.80(0.59,1.14)$ & 33.31 & $6.1(4.1,8.5)$ \\
\hline
\end{tabular}


Table 5. UVER exposure and ambient UVER (both given in SEDs) per day, measured using VioSpor dosimeters, and Exposure ratio for each of the solar height intervals, for 6-8 age group stratified by dosimeter position.

\begin{tabular}{|c|c|c|c|c|}
\hline & UVER exposure & SED/Hour Outdoor & Median & Exposure Ratio \\
\hline & Median ( 25,75 percentile $)$ & Median $(25,75$ & Ambient UVER & Median $(25,75$ \\
\hline & (SEDs) & percentile) & (SEDs) & percentile) $(\%)$ \\
\hline \multicolumn{5}{|l|}{ Solar Height 1} \\
\hline Sch. P.C. wrist & $1.40(1.03,2.13)$ & $0.56(0.38,0.72)$ & 12.84 & $11.5(7.5,16.9)$ \\
\hline Sch P.C. shoulder & $1.58(0.96,2.60)$ & $0.57(0.37,0.68)$ & 12.93 & $12.7(8.1,18.9)$ \\
\hline Sch. E.P. wrist & $0.53(0.41-0.90)$ & $0.33(0.19,0.58)$ & 11.90 & $5.0(3.1,7.7)$ \\
\hline Sch. E.P. shoulder & $1.08(0.66,1.38)$ & $0.43(0.31,0.59)$ & 11.90 & $7.9(5.9,13.2)$ \\
\hline Total for S. H. 1 & $1.33(0.88,2.18)$ & $0.57(0.37,0.73)$ & 12.84 & $10.7(6.8,17.4)$ \\
\hline \multicolumn{5}{|l|}{ Solar Height 2} \\
\hline Sch. P.C. wrist & $1.23(0.73,1.66)$ & $0.56(0.42,0.74)$ & 24.88 & $5.0(2.9,6.7)$ \\
\hline Sch. P.C. shoulder & $2.01(1.90,2.68)$ & $1.04(0.74,1.34)$ & 24.88 & $7.9(7.6,10.8)$ \\
\hline Sch. E.P. wrist & $2.25(1.40,2.76)$ & $0.77(0.66,0.96)$ & 27.14 & $8.2(4.8,10.3)$ \\
\hline Sch. E.P. shoulder & $2.38(1.42,3.61)$ & $0.84(0.53,1.20)$ & 27.14 & $8.9(5.5,13.3)$ \\
\hline Total for S. H. 2 & $1.93(1.15,2.85)$ & $0.76(0.54,1.16)$ & 25.28 & $7.6(4.6,10.8)$ \\
\hline \multicolumn{5}{|l|}{ Solar Height 3} \\
\hline Sch. P.C. wrist & $1.73(1.36,2.12)$ & $0.70(0.49,1.06)$ & 33.31 & $4.6(3.2,6.9)$ \\
\hline Sch. P.C. shoulder & $2.22(1.44,3.35)$ & $0.96(0.72,1.19)$ & 38.92 & $5.5(4.1,7.8)$ \\
\hline Sch. E.P. wrist & $2.99(2.60,3.46)$ & $1.00(0.87,1.15)$ & 37.00 & $9.0(7.7,10.8)$ \\
\hline Sch. E.P. shoulder & $2.23(1.81,3.31)$ & $0.77(0.62,1.14)$ & 29.25 & $6.9(4.8,9.3)$ \\
\hline Total for S. H. 3 & $2.11(1.45,2.73)$ & $0.80(0.59,1.14)$ & 33.31 & $6.1(4.1,8.5)$ \\
\hline
\end{tabular}


Table 6. UVER exposure and ambient UVER (both given in SEDs) per day, measured using VioSpor dosimeters, and Exposure ratio for each of the solar height intervals, for 10-11 age group stratified by

sex.

\begin{tabular}{|c|c|c|c|c|}
\hline & UVER exposure & SED/Hour Outdoor & Median & Exposure Ratio \\
\hline & Median ( 25,75 percentile $)$ & Median $(25,75$ & Ambient UVER & Median $(25,75$ \\
\hline & (SEDs) & percentile) & (SEDs) & percentile) $(\%)$ \\
\hline \multicolumn{5}{|l|}{ Solar Height 1} \\
\hline School P.C. girls & $1.15(0.62,1.69)$ & $0.39(0.21,0.50)$ & 9.88 & $9.6(7.1,10.8)$ \\
\hline School P.C. boys & $1.32(0.94,1.77)$ & $0.44(0.29,0.54)$ & 12.38 & $10.8(9.5,13.6)$ \\
\hline Total for S. H. 1 & $1.31(0.83,1.74)$ & $0.44(0.27,0.51)$ & 9.88 & $10.1(8.0,11.5)$ \\
\hline \multicolumn{5}{|l|}{ Solar Height 2} \\
\hline School P.C. girls & $1.76(1.38,2.13)$ & $0.52(0.40,0.69)$ & 22.16 & $7.1(5.6,9.1)$ \\
\hline School P.C. boys & $1.98(0.95,2.43)$ & $0.61(0.28,0.71)$ & 24.88 & $8.6(4.0,10.2)$ \\
\hline Total for S. H. 2 & $1.81(1.13,2.18)$ & $0.55(0.34,0.75)$ & 23.52 & $7.6(4.6,9.8)$ \\
\hline \multicolumn{5}{|l|}{ Solar Height 3} \\
\hline School P.C. girls & $1.38(0.99,1.93)$ & $0.42(0.29,0.60)$ & 37.08 & $3.8(2.6,7.3)$ \\
\hline School P.C. boys & $2.27(1.56,3.14)$ & $0.76(0.47,1.01)$ & 34.51 & $5.7(4.5,9.5)$ \\
\hline Total for S. H. 3 & $1.70(1.09,2.65)$ & $0.50(0.32,0.83)$ & 37.00 & $4.5(3.1,8.4)$ \\
\hline
\end{tabular}


Table 7. UVER exposure and ambient UVER (both given in SEDs) per day, measured using VioSpor dosimeters, and Exposure ratio for each of the solar height intervals, for 10-11 age group stratified by dosimeter position.

\begin{tabular}{|c|c|c|c|c|}
\hline & UVER exposure & SED/Hour Outdoor & Median & Exposure Ratio \\
\hline & Median ( 25,75 percentile $)$ & Median $(25,75$ & Ambient UVER & Median $(25,75$ \\
\hline & (SEDs) & percentile) & (SEDs) & percentile) $(\%)$ \\
\hline \multicolumn{5}{|l|}{ Solar Height 1} \\
\hline Sch. P.C. wrist & $1.08(0.90,1.74)$ & $0.41(0.28,0.53)$ & 14.87 & $10.1(6.5,11.3)$ \\
\hline Sch. P.C. shoulder & $1.35(0.83,1.71)$ & $0.45(0.27,0.50)$ & 9.88 & $10.1(8.5,11.6)$ \\
\hline Total for S. H. 1 & $1.31(0.83,1.74)$ & $0.44(0.27,0.51)$ & 9.88 & $10.1(8.0,11.5)$ \\
\hline \multicolumn{5}{|l|}{ Solar Height 2} \\
\hline Sch. P.C. wrist & $1.76(1.17,2.11)$ & $0.50(0.34,0.70)$ & 24.88 & $7.1(4.7,8.5)$ \\
\hline Sch. P.C. shoulder & $1.98(1.21,2.63)$ & $0.61(0.40,0.87)$ & 22.15 & $8.9(5.5,11.9)$ \\
\hline Total for S. H. 2 & $1.81(1.13,2.18)$ & $0.55(0.34,0.75)$ & 23.52 & $7.6(4.6,9.8)$ \\
\hline \multicolumn{5}{|l|}{ Solar Height 3} \\
\hline Sch. P.C. wrist & $1.56(0.95,2.84)$ & $0.47(0.26,0.84)$ & 34.51 & $4.3(2.5,8.2)$ \\
\hline Sch. P.C. shoulder & $1.73(1.26,2.27)$ & $0.50(0.36,0.76)$ & 38.92 & $4.5(3.2,8.5)$ \\
\hline Total for S. H. 3 & $1.70(1.09,2.65)$ & $0.50(0.32,0.83)$ & 37.00 & $4.5(3.1,8.4)$ \\
\hline
\end{tabular}

